\title{
GRAFIS LINGKUNGAN SEBAGAI MEDIA INFORMASI KOMUNIKASI VISUAL LUAR RUANG
}

\author{
Y. Andri Hervian Yunanto \\ Mahasiswa Pascasarjana ISI Yogyakarta, \\ Dosen Jurusan Disain Komunikasi Visual, \\ Akademi Seni Rupa dan Disain "MSD" Yogyakarta \\ Email: andrihervian@gmail.com
}

\begin{abstract}
Graphic environment is to make communication with people who visit or be somewhere. Directional information is a form of product creation graphic designer. Construction of something is bound to impact on environmental change as well as the development of sign systems. In fact so much chaos that emerged as a result. Sameness and conformity to the building does not guarantee harmony with the environment. Having regard to the natural environment, human needs, and the environment that is built up is expected to create a harmonious environment.
\end{abstract}

Keywords: Graphic environment, Sign systems, Harmonious

\section{Pendahuluan}

Disain Komunikasi Visual atau lebih umum disingkat $\mathrm{DKV}$, dahulu dikenal dengan sebutanatau istilah Disain Grafis. Beberapa kalangan baik praktisi maupun institusi, sampai sekarang masih popular dengan menggunakan nama itu. Kata "grafis" berdekatan dengan "grafika" yang berhubungan dengan dunia cetakmencetak. Medium cetak di atas kertas seperti koran, majalah adalah contoh produk yang dihasilkan. Awal perkembangan percetakan kertas dimulai sejak sebelum revolusi industri di Eropa dengan ditemukannya teknologi mesin cetak oleh Guttenberg. Hal ini menyebabkan kebutuhan akan tenaga yang menguasai ilustrasi, huruf (tipografi) dan tata letak meningkat. Tenaga pendukung perkembangan industri itu lazim disebut sebagai disainer grafis. Kata Disain Grafis itu sendiri pertama kali digunakan pada tahun 1922 di sebuah esai berjudul New Kind of Printing Calls for New Design yang ditulis oleh William Addison Dwiggins, seorang desainer buku Amerika (Livingston et.al. London: 1992)

Disain Komunikasi Visual tidak hanya terbatas pada urusan gambar yang bagus atau mengkombinasi dan menata dengan rapi huruf- huruf agar lebih mudah untuk dibaca, akan tetapi pesan informasi yang ada di dalamnya juga harus mudah ditangkap dan dimengerti oleh penonton (target audient). Desain Grafis kemudian dapat dimaknai usaha manusia untuk memecahkan permasalahan visual yang berupa gambar (ilustrasi), huruf (tipografi) dan tata letak (layout) yang diharapkan mempunyai kemampuan menyampaikan pesan kepada penontonnya. Pengistilahan disain grafis mengalami perubahan, untuk mengakomodasi keperluan yang lebih luas, maka dengan lebih menitikberatkan pada proses komunikasi, visual dan audio visual, mengubah paradigma sebutan disain grafis menjadi disain komunikasi visual (DKV) (Banindro, 2009:5)

Disain Komunikasi Visual tidak terpaku pada media konvensional dua dimensi (2D) namun lebih bervariasi dan berkembang. Eksplorasi tiga dimensi (3D) menjadi lebih luas salah satunya adalah adaptasinya dengan lingkungan sehingga menjadi bagian yang dikreasikan menjadi media. Bersinggungan dengan lingkungan, desain komunikasi visual juga tidak hanya memperindah akan tetapi dapat memecahkan pemasalahan komunikasi dalam lingkungan dimana desain 
tersebut berada.

Dalam teori Wastu Citra, wastu-nilai guna (manfaat) dan citra-keindahan (penuh dengan makna), maka kata 'guna' tidak hanya menunjuk pada cara pemanfaatan dan keuntungan fungsional yang bisa pemakai dapatkan saja, akan tetapi juga sebagai sesuatu yang mempunyai kemampuan untuk meningkatkan kualitas hidup kita. Citra menunjuk pada sesuatu yang transendens, yang memberi makna. Citra mencakup estetika, kenalaran ekologis, karena mendambakan sesuatu yang laras, suatu kosmos yang teratur dan harmonis. (Mangunwijaya, 2009)

\section{Studi Kasus}

\section{Green School Bali}

Sekolah alam di Bali, Green School - KulKul Campus yang mulai dibangun pada tahun 2009 dan didirikan oleh John Hardy, seorang desainer dan pengusaha jewelry. Material bangunan yang terdiri dari bambu sangat mudah di dapatkan dan harganya murah dibandingkan dengan bahan baku kayu. Bambu yang juga mempunyai nilai guna sebagai bahan baku yang lentur dan kuat. Bambu mempunyai bentuk artistik sangat baik dan indah.

Pemanfaatan bambu sebagai bangunan utama juga untuk hal-hal yang sederhana. Dari struktur bangunan utama menggunakan bambu sebagai tiang-tiang penyangga. Selain itu juga sistem papan informasi (sign system) untuk pengunjungpun dibuat menggunakan material bambu. Potongan bambu utuh atau sudah dibelah kemudian diberi tulisan yang beisi informasi lokasi-lokasi yang dibutuhkan pengunjung. Penulisan tipografi menggunakan ketrampilan tangan dengan menyayat kulit batang bambu menghasilkan bentuk huruf yang jelas untuk dibaca. Keselarasan antara lingkungan dengan kreasi membentuk citra yang dapat memberi kesan sangat harmonis dengan lingkungan alam sekitar.

\section{Candi Prambanan}

Candi Prambanan yang dibangun pada tahun 835-856 oleh wangsa Sanjaya, merupakan candi Hindu yang memiliki tiga candi utama yaitu Brahma, Wisnu dan Siwa. Bangunan candi menghadap ke timur. Setiap candi utama berhadapan dengan candi lain sebagai kendaraan masing-masing dewa. Keenam candi tersebut

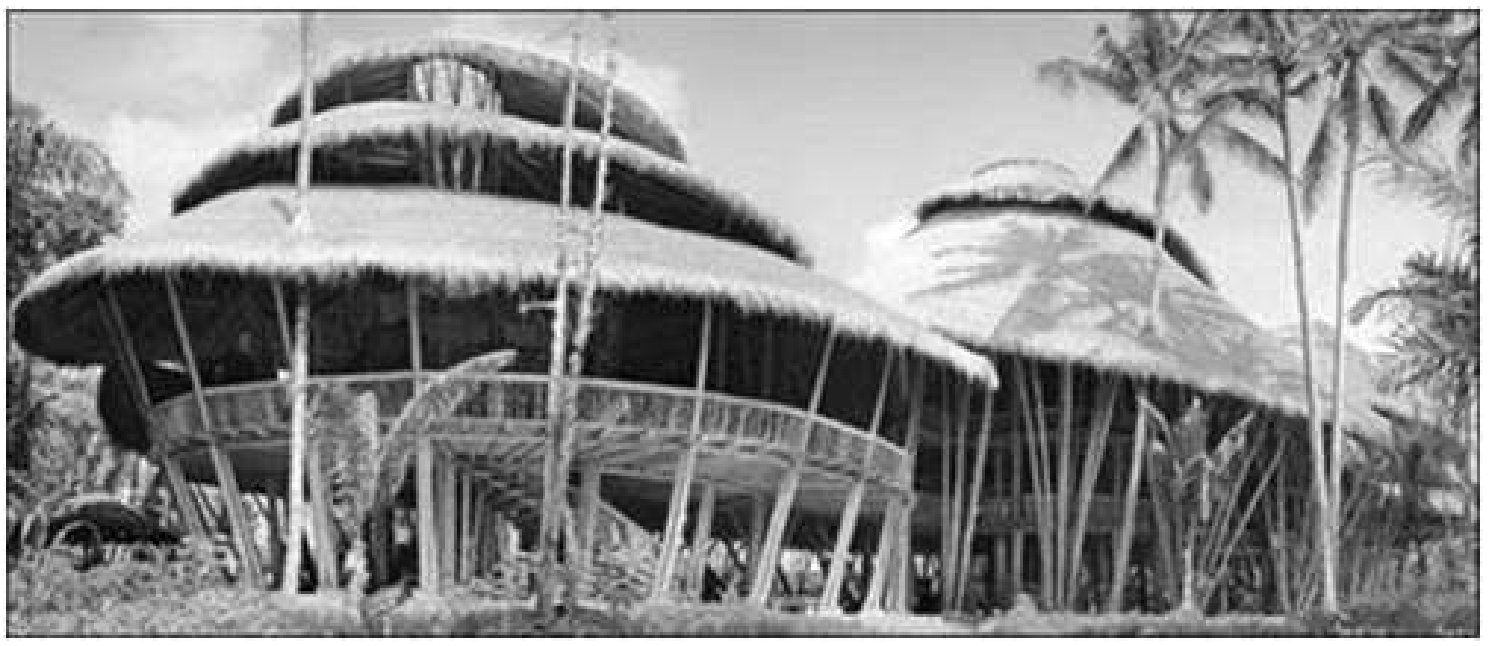

Gambar 1.

Bangunan Green School di Bali dengan material bambu membuat suasana lebih alami (Sumber: http://blogs.fco.gov.uk/paulmadden/files/2013/07/green-school.jpg) 
berdiri di atas ketinggian pelataran yang sama. Sedangkan ada 224 candi kecil (perwara atau penjuru) yang berada di pelataran yang tingginya lebih rendah. (Sopandi, 2013:30-32)

Di sebelah utara Candi Prambanan terdapat pula Candi Sewu. Candi Sewu merupakan candi Budha. Luasnya area candi Prambanan yang sekarang ini dikelola dalam satu atap yaitu P.T. Wisata Taman Candi (Borobudur, Prambanan, \& Boko)

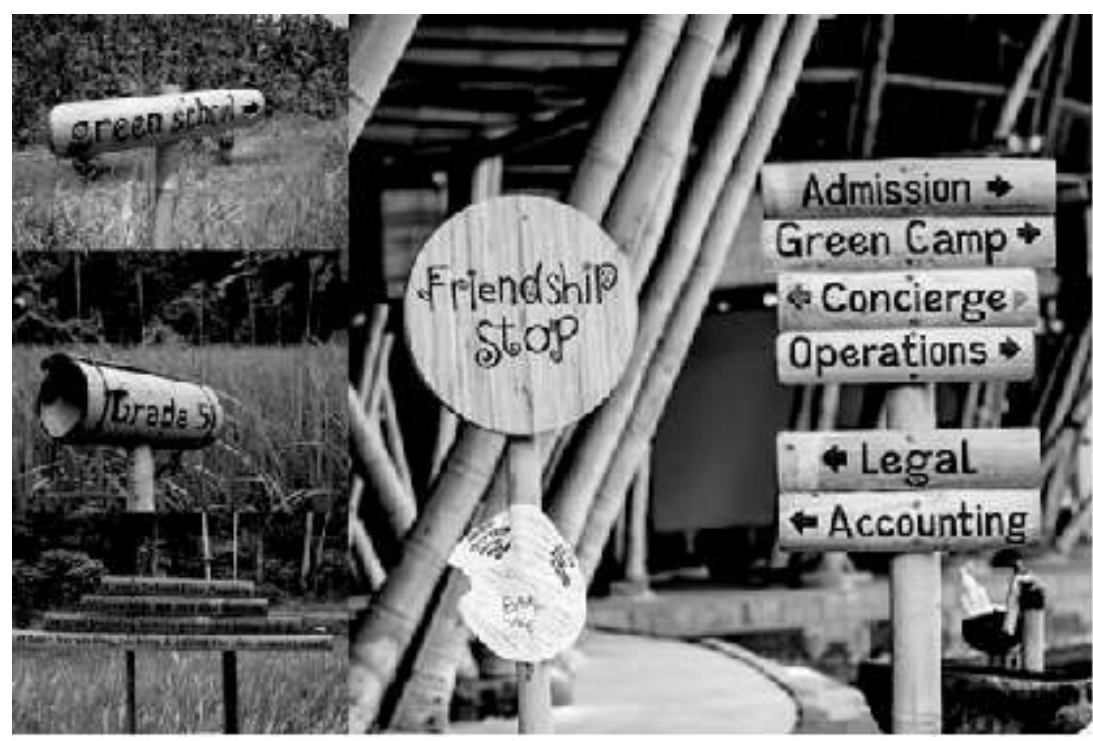

Gambar 2.

Grafis Lingkungan informasi di Green School Bali, dengan material bamboo, tampak menyatu dengan lingkungan di sekitar bangunan.

(Sumber: http://sharingtheworldtogather. blogspot.com/2010/12/green-school-bali.htm)

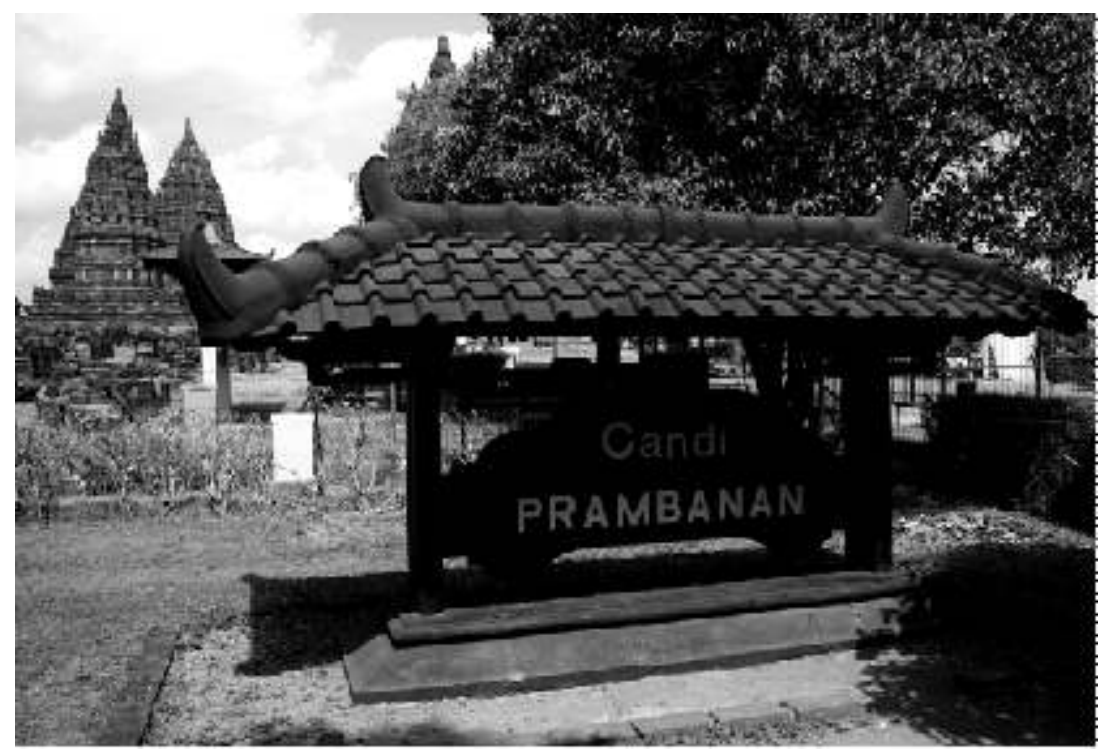

Gambar 3.

Grafis Lingkungan untuk menunjukkan keberadaan candi Prambanan diantara candi yang lain (Foto: Andri Hervian, 2013) 
Sistem papan informasi (sign system) yang ada di candi Prambanan terdiri atas berbagai macam material. Terdapat bentuk tanda untuk menginformasikan nama candi menggunakan kayu dan material lain seperti genteng, dan batu tatah untuk alas. Beberapa papan petunjuk arah untuk pengunjung menggunakan besi dan cat semprot. Bentuk dan ornamen atau elemen penghias disesuaikan dengan bentuk yang ada disekitar candi yaitu berlanggam bentuk lapik candi.

Dari contoh di atas terdapat berbagai macam bentuk model sign system yang terdapat pada masing-masing area. Disainer dengan berbagai cara berupaya bagaimana agar tanda yang dibuat dapat membantudan mempermudah aktivitas komunikasi yang akan dilakukan dalam satu wilayah. Sign yang dibuat tersebut tentu memberikan dampak terhadap lingkungan.

\section{Pembahasan}

Penyediaan Informasi menjadi penting untuk mengetahui daerah yang asing bagi para pengunjung. Informasi menjadi kebutuhan manusia dalam sebuah lingkungan yang baru khususnya untuk menjalankan semua aktifitas. Tempat atau lingkungan yang baru membutuhkan sistem informasi yang baik. Orang yang datang ke tempat tersebut tidak asing atau bahkan dibuat bingung apabila tidak tahu apa yang akan dikerjakan. Dengan bantuan gambar dan penjelasan informasi lisan dan tulisan yang lengkap pengunjung jadi semakin tahu dan diharapkan mempunyai ide, gagasan untuk beraktifitas selanjutnya..

Gambar dan informasi yang mudah dipahami serta tidak menimbulkan makna yang beda ketika disampaikan sangat membantu proses komunikasi kepada penunjung. Dalam hal ini telah

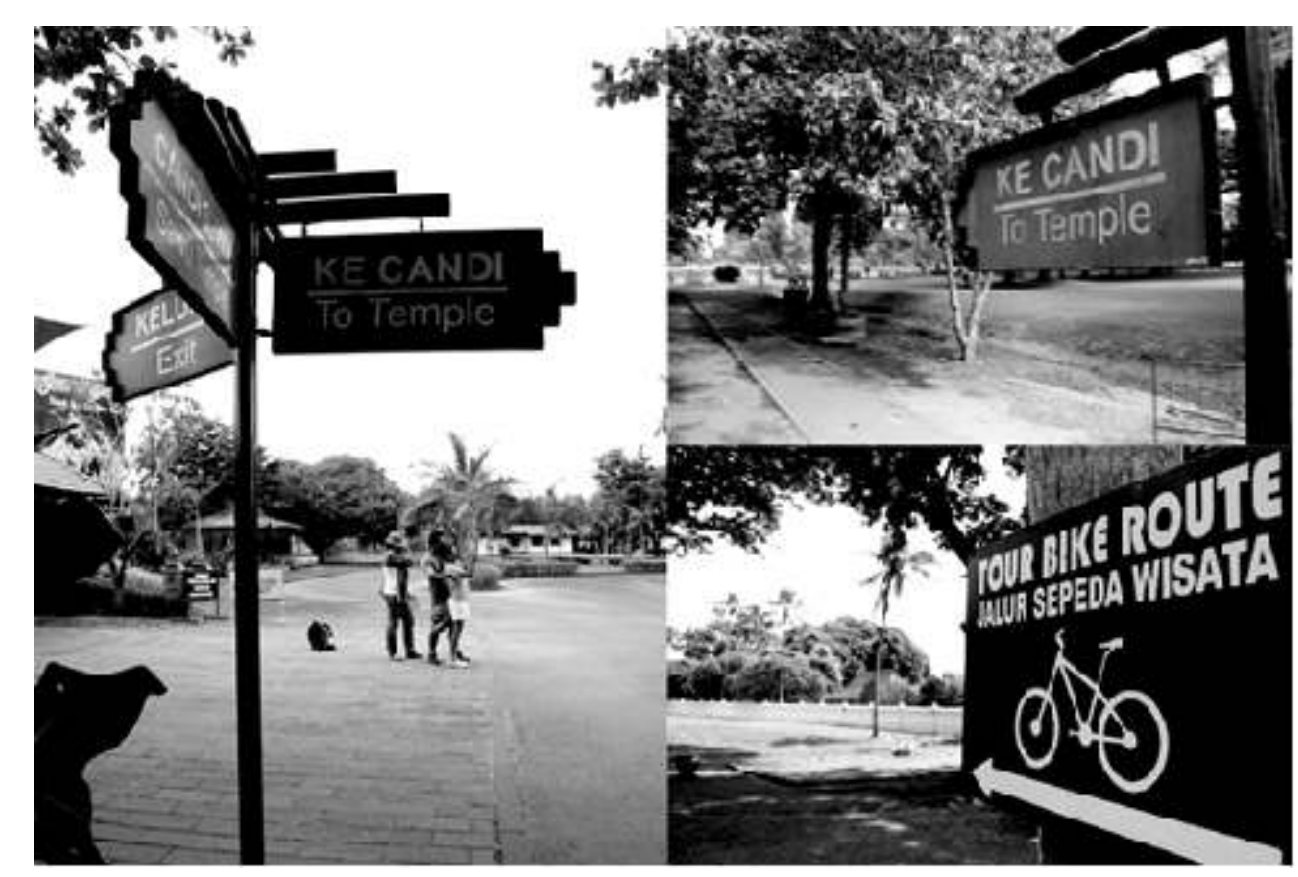

Gambar 4.

Grafis Lingkungan di Candi Prambanan menggunakan material baru, untuk menghindari salah persepsi pengunjung seandainya dibuat dengan material batu. (Foto: Andri Hervian, 2013) 
terdapat gambar-gambar symbol yang sudah berkembang dan ada dalam masyarakat. Environment Graphic Design atau dapat disebut juga Grafis Lingkungan, adalah istilah yang digunakan sekitar tahun 60an dan booming tahun 70an, di saat kebutuhan akan arsitektur dan pertumbuhan ruang terbuka menjadi sangat kompleks (http://www.slideshare.net/sidkid1/ environmental-graphics).

Saat ini bidang tersebut dianggap menjadi bagian dari cakupan bidang disain komunikasi visual, walaupun muncul pula klaim bahwa bidang ilmu lain seperti arsitektur menganggap grafis
Upaya yang harus diciptakan bagi desainer grafis adalah menciptakan desain yang menyatu dengan lingkungan yang ada. Setiap karya desain selalu mempunyai pesan yang tersembunyi maupun nampak jelas (kontras) namun sebagai bagian dari lingkungan haruslah mempunyai konsep yang benar-benar digali dari akar yang ada di lingkungan tersebut.

Menurut Schmid dalam bukunya Biologische Architektur hubungan antara lingkungan, manusia dan pembangunan dapat digambarkan sebagai berikut:

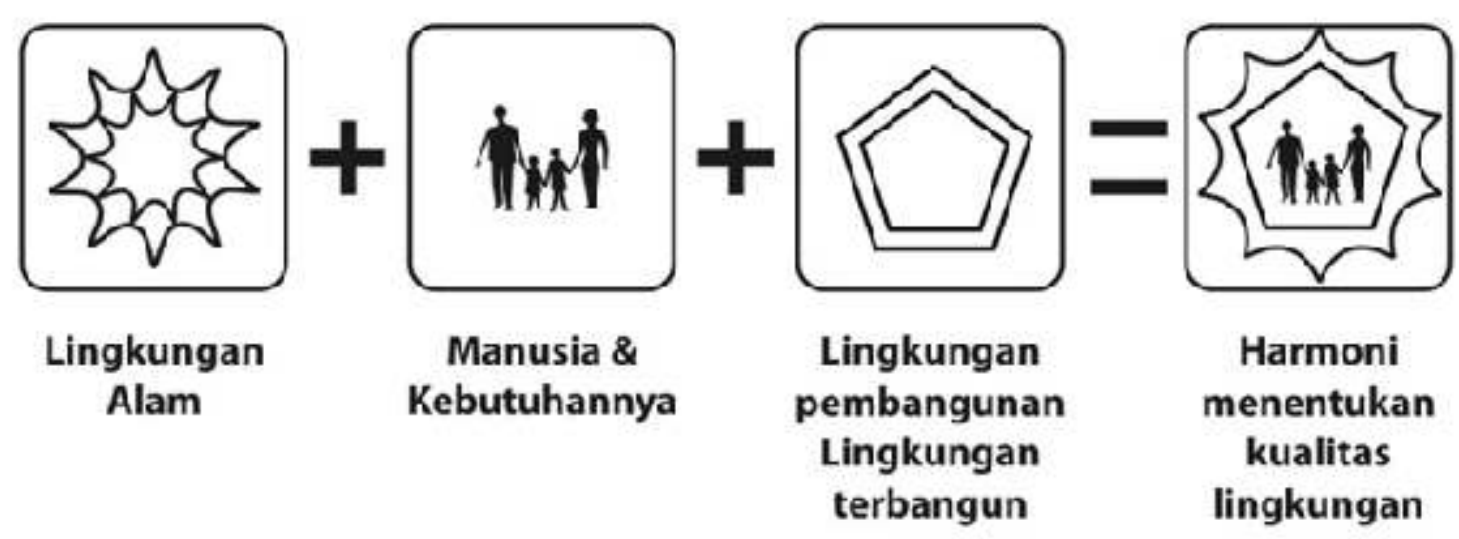

Gambar 5.

Hubungan pembangunan antara manusia, lingkungan alam dan dampaknya (sumber: Arsitektur \& Lingkungan, Heinz Frick, 1996)

lingkungan menjadi bidang pekerjaan yang melekat didalamnya. Adapun bidang garapan grafis lingkungan antara lain meliputi: environmental graphics, architectural graphics, way finding, signage dan super graphics. (Environmental graphics ppt., Guru Sidhu on Dec 06, 2012) Proses komunikasi menjadi kunci untuk berkomunikasi dengan penonton (target audient) dan dapat menyampaikan informasi yang tepat sehingga dapat membantu seluruh aktivitas yang diinginkan pengunjung.
Keseimbangan dengan alam, seimbang dengan manusia, seimbang dengan lingkungan yang terbangun. Jika semuanya harmonis maka kualitas lingkungan manusia akan memuaskan. Akan tetapi pengaruh-pengaruh tersebut di atas amat sering berbenturan. Kehidupan manusia yang seimbang dengan alam akan membutuhkan pengertian baru bagi istilah-istilah yang ada, seperti misalnya pengertian waktu, ruang, ukuran, fungsi, lingkungan dan sebagainya (Heinz, 1996: 13-14) 


\section{Material Grafis Lingkungan}

Pada kasus sekolah alam di Bali mengangkat tema utama yaitu alam. Alam merupakan unsur yang paling dominan sekali. Bambu menjadi inspirasi sebagai material dasar yang dipilih untuk membantu penciptaan beberapa sign nantinya. Pohon bambu yang mudah dijumpai pada pedesaan di sekitar tempat itu dan murah sangat membantu mempermudah material yang ada untuk disusun sesuai yang diinginkan. Pengerjaan batang bambu juga cukup mudah untuk dipotong, diikat, dirangkai menjadi sebuah bentuk. Dari segi kualitas bambu memang tidak sekuat apabila dibandingkan dengan kayu dengan kualitas terbaiknya namun pertimbangan kelenturan mudah dibentuk dan juga nilai ekonomis yang murah. Bambu pada lingkungan terbuka cukup efisien sebagai material terbukti sejak jaman dahulu.

Sedangkan pada candi Prambanan material batu kali tidak digunakan dalam pembangunan sign system, dalam hal ini konteksnya mendasarkan pada pengertian tentang waktu. Prambanan yang dibangun pada tahun 800an tersebut, akan menjadi membingungkan bagi pengunjung apabila terdapat tanda sign yang terbuat dari batu buatan masa modern ini. Hal ini diungkapkan oleh Boy Gilang Budiman sebagai disainer yang ikut mengerjakan sistem informasi visual pada candi Prambanan yang dibantu para ahli dari luar negeri sebagai konsultan.

\section{Tanda sebagai simbol}

Semiotik adalah segala sesuatu yang berhubungan dengan system tanda atau lambang dalam kehidupan manusia. Tanda (Sign) adalah segala sesuatu yang ada di muka bumi yang sebelumnya melewati proses kesepakatan bersama (konfensi) sebagai rujukan atau reverensi akan sesuatu yang lain (Umberto Eco, 1979)

Sign system sangat berguna sebagai petunjuk lokasi, mengarahkan orang berpindah dari satu lokasi ke lokasi lain. Fungsi dari sign system adalah mengidentifikasi, menginformasikan dan mengarahkan lewat beragam petunjuk dari fasilitas yang disediakan. Sign yang diharapkan diletakan pada tempattempat transisi dimana orang mengambil keputusan untuk meneruskan arah perjalanan yang ditempuh ataupun mengubah rute

Menurut William Moris semiotic dibagi dalam 3 bagian yaitu : Sintaktik, Semantik dan Pragmatik. Sintaktik yaitu hubungan antara bentuk visual yang satu dengan yang lainnya dan struktur model formal yang mewakili suatu keterangan. Sedangkan Semantik adalah hubungan suatu image dengan arti atau makna.

Dalam hal ini ikon yang diciptakan dapat dikenal oleh pengujung sebagai fasilitas yang ada. Pragmatik adalah hubungan antara suatu bentuk visual (sign) dengan manusia sebagai pengunanya. Kepragmatisan dalam sistem tanda yang dimaksud di kedua objek contoh diatas, terkait dengan aspek teknis ukuran yang secara matematis dan optis dengan mudah dan ideal dapat terbaca oleh penonton. (Morris, 1938) Dari kedua contoh baik di Prambanan maupun di Green School, penggunaan bahasa verbal baik Indonesia maupun bahasa Inggris secara sederhana (present), karena dianggap secara semantik memudahkan audien menangkap arti dan makna secara universal.

\section{Kesimpulan}

Informasi dalam bentuk grafis lingkungan suatu tempat dapat dibuat dengan mengolah kekayaan dari area lingkungan setempat. Pembangunan tanpa merusak lingkungan adalah kekuatan dari grafis lingkungan, dengan 
memberikan sentuhan gambar, tipografi, warna sesuai setting, akan mempunyai nilai estetika (citra) yang tinggi. Dengan tanpa mengabaikan pesan yang ingin disampaikan sebagai media informasi, grafis lingkungan sekaligus bermanfaat meningkatkan nilai kehidupan.

Pada objek wisata, pengunjung akan menjadi berhati-hati karena membaca tanda atau pesan sehingga pengunjung selamat atau tertolong atau menjadi terbantu dari keterasingan karena terdapat grafis informasi yang dengan cepat dapat menemukan apa yang dicari atau segera memperoleh informasi dalam satu kawasan area.

Pembangunan struktur candi Prambanan dan konsep sign system yang tidak dibangun dalam waktu yang bersamaan dapat diatasi dengan metoda semiotik, sehingga jelas nyata kurun waktu pembuatan sign tersebut, maknanya ialah telah dilanjutkan oleh generasi yang berbeda. Hal ini dimaksudkan untuk tidak membingungkan bagi pengunjung.

Lain halnya dengan Green School yang ingin menyatukan antara bentuk material bangunan dengan bentuk disain atau perabot yang lain yang kemunculanya "saat ini" sehingga makna komunikasi visualnya selain menyatu juga harmoni. Keharmonisan dengan alam tidak harus sama, asal selaras. Pemahaman akan lingkungan alam, kebutuhan manusia dan lingkungan yang terbangun, akan mendapatkan harmoni dengan sendirinya, dimana peran grafis lingkungan nantinya juga akan berperan/mendukung lingkungan alam di sekitarnya. 


\section{Daftar Pustaka}

Banindro, Baskoro Suryo, Sejarah Lahirnya Sekolah Reklame, dari ASRI, STSRI "ASRI" hingga FSR ISI Yogyakarta, Prodi DKV, Yogyakarta. 2009

Eco, Umberto, A Theory of Semiotic. Indiana University: Indiana University Press, Bloominton 1979

Heinz, Frick., Arsitektur dan Lingkungan, Kanisius, Yogyakarta, 1996

Livingston, Alan and Isabella., 'Dictionary of graphic design and designers'. London: Thames and Hudson, 1992

Mangunwijaya Y.B. , Wastu Citra. PT. Gramedia Pustaka Utama, Jakarta 2009

Morris W. Charles, Foundations of the Theory of Sign, 1938

Sopandi, Setiadi, Sejarah Arsitektur Sebuah Pengantar, PT. Gramedia Pustaka Utama, Jakarta, 2013

Schimd, Peter, Bio-logische Architektur ( $2^{\text {nd }}$, ed. $)$, Koln, 1983

Vihma Susan dan Vakeva Seppo, Semiotika Visual dan Semantika Produk, Jalasutra, 2009

http://www.slideshare.net/sidkid1/environmentalgraphics 